\title{
o Impacto da Distância no Valor Investido em Equity Crowdfunding no Brasil
}

\section{The Impact of Distance on the Value Invested in Equity Crowdfunding in Brazil}

\author{
Luisa de Souza Nascimento \\ Escola de Administração de Empresas de São Paulo - EAESP/FGV - Brasil \\ luisadsnascimento@gmail.com \\ ORCID: 0000-0003-0664-3499 \\ Eduardo de Rezende Francisco \\ Escola de Administração de Empresas de São Paulo - EAESP/FGV - Brasil \\ eduardo.francisco@fgv.br \\ ORCID: 0000-0001-8895-2089 \\ Israel José dos Santos Felipe \\ Universidade Federal de Ouro Preto - UFOP- Brasil \\ israelfelipe@ufop.edu.br \\ ORCID: 0000-0001-8608-0029
}

Submetido em 18/11/2019; Aprovado em 05/02/2020.

\section{Resumo}

Objetivo: Estudos apontam uma correlação negativa da distância investidores-investidas e a capacidade de empresas jovens levantarem capital. No entanto, essa lógica não permanece no Crowdfunding, onde foram encontrados indícios de maior dispersão geográfica. Este estudo investiga o impacto da distância sobre o valor dos investimentos no mercado do Equity Crowdfunding (ECF), modalidade na qual startups oferecem quotas de participação para pequenos investidores através de plataformas online. Metodologia: Para testar a hipótese de que a distância não impacta o valor investido utilizou-se a população de investidores e empresas da plataforma Broota (hoje Kria) entre 2015 e 2016 e dados geoeconômicos do Instituto Brasileiro de Geografia e Estatística (IBGE) (2010). Aplicou-se técnicas de georreferenciamento para calcular a distância e regressões múltiplas para determinar as melhores variáveis na explicação do investimento. Modelos Espacial Auto-Regressivo (SAR) e Geographically Weighted Regression (GWR) foram utilizados para estudar o impacto da vizinhança no valor investido. Resultados: A técnica GWR teve o melhor ajuste $\left(\mathrm{R}^{2}\right.$ de $\left.10,42 \%\right), 1,11 \%$ maior do que o obtido com a Regressão Linear Múltipla. Conclui-se que a geografia é significante (modelos SAR e GWR apresentam efeito similar), mas não tem grande impacto no valor investido. Ademais, os investidores de ECF comportam-se similarmente ao de investimentos tradicionais, o que indica que essa modalidade não alcança eficientemente empreendimentos fora dos grandes centros urbanos. Contribuições teóricas: Este artigo ajuda a entender o comportamento de investidores brasileiros, onde essa modalidade ainda é nova e pouco estudada. Contribuições práticas: As conclusões podem ser úteis para a formulação de políticas para incentivo de financiamento de empresas em regiões fora do eixo sul-sudeste.

Palavras-chave: equity crowdfunding, valor investido, distância geográfica, startups.

\section{Abstract}

Objective: Studies have shown a negative correlation between distance of investors and enterprises and the capacity of new ventures raise funds. However, this pattern does not stand in Crowdfunding, where were found evidences of large geographic dispersion. This study investigates the impact of distance on the value of investments in the Equity Crowdfunding market (ECF), modality where startups sell shares for retail investors using online platforms. Methodology: To test the hypothesis that distance does not impact the value invested we used the database of investors and enterprises from Broota platform (now Kria) between 2015 and 2016 and geoeconomic data from Instituto Brasileiro de Geografia 
e Estatística (IBGE) (2010). Georeferencing technics were used to calculate the distance and multiple regressions to select the variables that impact most the investment. Spatial autoregressive model (SAR) e Geographically Weighted Regression (GWR) were used to determine the impact of neighborhood on the value invested. Results: The GWR technique had the best adjustment $\left(R^{2}=10,42 \%\right), 1,11 \%$ higher than the result from Multiple Linear Regression. We concluded that the geography is relevant (SAR and GWR models have similar effects), but has not a higher impact on the value invested. The ECF investor has a similar behavior to traditional investors, this means that the modality does not efficiently reach enterprises away from big cities. Theoretical contributions: This article helps understanding the behavior of brazilians investor, where ECF still new and little studied. Practical contributions: The conclusion may be used for policy making of incentives for companies away from Brazil's biggest urban centers.

keywords: equity crowdfunding, invested value, geographic distance, startups.

\section{Introdução e motivação}

As micro e pequenas empresas têm apresentado dificuldade na obtenção de crédito para o desenvolvimento de suas atividades iniciais (Hildebrand, Puri \& Rocholl, 2016). A cobrança de um histórico de informações financeiras (Ryan, O’Toole \& McCann, 2014) e garantias, que envolvem até mesmo o patrimônio do empreendedor (Berger, Espinosa-Vega, Frame \& Miller, 2011), são bons exemplos de rígidos critérios para a concessão do crédito para diversas instituições financeiras. Essa política evidencia a necessidade de algum mecanismo ou até mesmo tecnologia capaz de suavizar as restrições econômicas impostas pelas fontes tradicionais de crédito (Mollick \& Robb, 2016) e por crises financeiras (Anbil, 2018).

O Equity Crowdfunding (doravante ECF) é um exemplo de inovação em produtos financeiros. Esse modelo financeiro incorpora tecnologias para unir investidores e empreendedores que buscam financiamento em plataformas virtuais. 0 financiamento via ECF ocorre mediante aportes de diversos investidores que, quando são contabilizados, devem igualar ou superar a meta financeira atribuída ao empreendimento (Felipe, 2015).

O surgimento do ECF, em 2012, passou a permitir que pequenos investidores comprassem participações em startups, antes isso só era possível através de Fundos de Investimento (Forbes, 2012). ECF é um tipo de Crowdfunding no qual as startups vendem quotas através de plataformas digitais, o que é definido como "Mini-IPO". A inovação está no fato de que qualquer pessoa, respeitando algumas restrições legais (ver instrução Comissão de Valores Mobiliários (CVM) 58811), pode investir em startups. Essa característica tem atraído um variado conjunto de empreendimentos, em setor e escala, gerando um rol de oportunidades para empreendedores e investidores (Wang, Mahmood, Sismeiro, \& Vulkan, 2019). 0 ECF tem se apresentado como uma importante ferramenta na democratização de fontes de financiamento e oportunidades de investimento (Felipe, 2017).

As plataformas de Crowdfunding podem reduzir a necessidade de networking para conectar investidores e empreendedores (Guenther, Johan, \& Schweizer, 2018; Zhang, Juan, Dan, \& Yaokuang, 2018). Os menores montantes requeridos e a utilização da internet como meio de divulgação dos projetos também servem para tornar essa modalidade mais acessível e de longo alcance. Como microinvestidores, as pessoas que investem através do Equity Crowdfunding não participam ativamente da gestão da empresa (diferentemente do que acontece com investidores anjo) e toda a negociação e comunicação entre os envolvidos são feitas online.

Ainda que as fontes de capital tenham aumentado, permanece a necessidade de proximidade física entre o investidor e a empresa (Agrawal, Catalini, \& Goldfarb, 2011). No Brasil, 36,7\% das Gestoras de Private Equity ficam a menos de $50 \mathrm{~km}$ de distância das empresas investidas (Ventura, 2015). Agrawal et al. (2011) e Agrawal, Catalini, \& Goldfarb, (2014) apontam que a maioria dos investidores de empresas em seus primeiros anos são locais, porque nas primeiras fases é necessário um maior monitoramento e a distância geográfica dificulta o processo de funding. Assim sendo, é razoável admitir que o ECF seja capaz de romper com a lógica tradicional da proximidade física entre empreendimento-investidor, uma vez que toda a interação entre essas partes é operacionalizada por uma plataforma online.

A literatura inicial acerca desta temática aponta que o ECF pode ser capaz de reduzir essa dependência geográfica (Vulkan, Åstebro, \& Sierra, 2016; Guenther et al., 2018), entretanto estudos recentes como o de Zhang et al. (2018) e Schwienbacher (2019), evidenciam que nem sempre isso acontece e que 
o ECF carece de maiores investigações, particularmente, no que diz respeito a elementos que possam influenciar nos investimentos realizados nesse mercado. Por se tratar de uma modalidade relativamente nova, o número de estudos que mostram o quanto a proximidade geográfica pode ser relevante, é bastante reduzido (Felipe, Mendes-Da-Silva \& Gattaz, 2019). Isto posto, o objetivo deste trabalho é verificar se, assim como no Private Equity e Venture Capital (Ventura, 2015), a distância é relevante na decisão de investimento no Equity Crowdfunding.

A pesquisa analisou dois aspectos, a saber: (i) o quanto a distância interfere na decisão de investimento, e (ii) o quanto a distância interfere no valor investido. Busca-se analisar a distribuição do número de projetos investidos e do montante total investido por distância para se alcançar os objetivos descritos. Dado que a distribuição de pessoas e PIB é desproporcional entre os Estados brasileiros, almeja-se utilizar variáveis que descrevam a população e o PIB das Unidades de Federação, ao se prever o investimento. Com isso, procura-se destrinchar o quanto o valor varia pela distância e não por outras características socioeconômicas. Também são consideradas características intrínsecas das empresas, como estágio (se é uma empresa recém-criada ou em expansão) e categoria de negócio, isso porque essas variáveis influenciam diretamente no risco percebido e empresas em seus primeiros anos são consideradas mais arriscadas (Seedinvest, 2016). Ademais, alguns segmentos de negócio são vistos como menos seguros que outros (Brown, Mawson, Rowe, \& Mason, 2018; Anglin et al., 2019).

A relevância do tema se dá pela importância das startups como ferramentas de desenvolvimento econômico e inovação. Segundo a Associação Brasileira de Startups (2019), startups são responsáveis por $50 \%$ dos novos empregos no Brasil. De acordo com o SEBRAE (2019), em 2018, pequenos negócios geraram o maior número de postos de trabalhos dos últimos quatros anos. 0 entendimento de formas alternativas de investimento pode ajudar pequenos empresários, especialmente os que ficam afastados dos grandes centros urbanos, a conseguirem aportes, viabilizar seus empreendimentos e com isso contribuir para o desenvolvimento de regiões mais afastadas no país.

No presente estudo, consideramos os dados fornecidos pela Broota (atualmente chamada de KRIA), a primeira plataforma de ECF do Brasil. O conjunto de observações contempla todos os projetos e investidores que utilizaram a plataforma entre 2015 e 2016. Analisamos 63\% do total de empreendimentos financiados por ECF no Brasil, conforme apontou a CVM (2016). Como estratégia empírica, adotamos modelos de regressão múltipla convencional e espaciais (SAR e GWR), os quais permitiram a estimação do efeito da distância geográfica sobre o valor investido em ECF. Nossos principais resultados sugerem que os investidores de ECF apresentam uma dispersão geográfica maior do que a observada em Private Equity e Venture Capital.

A grande maioria dos investidores estava concentrada entre $0 \mathrm{~km}$ e $50 \mathrm{~km}$ das investidas, ou seja, nota-se uma considerável restrição no número de investimentos em função do aumento da distância geográfica. Além disso, o número de investidores de ECF só se elevou quando as faixas de distância seguiam as capitais dos estados. Tais achados permitem concluir que a modalidade de investimento em ECF é mais popular, especialmente, em regiões metropolitanas. Somado a isso, o valor investido foi reduzido em função do aumento da distância geográfica entre investidor e investida. É possível presumir que o ECF ainda não conseguiu suavizar a sensibilidade do investidor à distância, ou seja, pelo menos a nível de mercado brasileiro, parece existir um home bias.

Este trabalho está dividido em cinco seções. A primeira apresentou a introdução e a motivação do trabalho. A segunda seção, por sua vez, apresenta o referencial teórico que embasa o trabalho. Na terceira, apresentamos o método do estudo. Os resultados são evidenciados e discutidos na quarta seção. E, por fim, na quinta seção, são destacadas as contribuições e implicações da pesquisa.

\section{Revisão de Literatura e Hipótese}

\subsection{Crowdfunding}

O Crowdfunding (doravante CF) é um tipo de Funding, "termo utilizado para designar as ações de indivíduos e organizações para o levantamento de capital para organizações, ações, projetos e iniciativas específicas" (Riffel, 2016). 0 CF utiliza plataformas online durante todas as etapas do processo de captação de recursos e alocação de investimentos (Hornuf \& Schwienbacher, 2018). Essas plataformas assemelham-se ao mercado de ações, dado que funcionam como um local de ofertas de empresas ou projetos em um ambiente altamente competitivo (Kabylka, 2016; Short et al., 2017). Existem quatro tipos 
de CF: Donation, Equity, Debt e Reward. Eles se diferenciam pela finalidade da arrecadação e retorno para os investidores (Crowdsourcing.org (2012)).

o Debt e Equity Crowdfunding têm retornos monetários (juros sobre o valor investido e participação na empresa, respectivamente). Essas modalidades têm um alto controle legislativo e exigem um maior esforço por parte do investidor para conseguir investir. A relação entre o investidor e empreendedor é de longo prazo (Kabylka, 2016).

O Donation e Reward têm retornos não monetários e a motivação para investir é poder contribuir para uma causa social ou receber uma recompensa material. A Tabela 1 destaca as principais diferenças entre as modalidades.

Tabela 1 - Características dos tipos de Crowdfunding

\begin{tabular}{|c|c|c|c|c|}
\hline Nome & Donation & Equity & Debt & Reward \\
\hline Tipo de retorno & $\begin{array}{l}\text { Benefício In- } \\
\text { tangíveis }\end{array}$ & $\begin{array}{l}\text { Participação em } \\
\text { empresas }\end{array}$ & $\begin{array}{l}\text { Dinheiro investido } \\
\text { mais juros }\end{array}$ & $\begin{array}{l}\text { Não financeiras (ex: amos- } \\
\text { tras de produtos) }\end{array}$ \\
\hline Valor médio investido & Baixo & Alto & Alto & Baixo \\
\hline Nível de controle legislativo & Baixo & Alto & Alto & Baixo \\
\hline Facilidade para investir & Fácil & Complexo & Complexo & Fácil \\
\hline $\begin{array}{l}\text { Durabilidade esperada do rela- } \\
\text { cionamento entre investidor e } \\
\text { empreendedor }\end{array}$ & Curto prazo & Longo prazo & Longo prazo & $\begin{array}{l}\text { Curto prazo (termina após } \\
\text { o investidor receber a re- } \\
\text { compensa) }\end{array}$ \\
\hline
\end{tabular}

Fonte: Adaptada de Kabylka (2016)

\subsection{Equity Crowdfunding}

Dentre as modalidades de CF, o Equity Crowdfunding se destaca pelo seu rápido crescimento. Em 2017, o mercado mundial movimentou cerca de R 8 bilhões (Crowdinvest, [2017?]). No Brasil, a primeira plataforma de ECF, Broota, foi criada em maio de 2014 e teve seu primeiro cliente em outubro do mesmo ano (EXAME, 2017). Desde então surgiram novas plataformas, mas a prática só foi regulamentada pela CVM em 13 de julho de 2017.

A regulamentação suavizou algumas regras, por exemplo, o limite de ofertas passou de $\mathrm{R} \$ 2,4 \mathrm{mi}$ lhões por ano para $\mathrm{R} \$ 5$ milhões. O limite de faturamento dos emissores aumentou de $\mathrm{R} \$ 3,6$ milhões ao ano para $\mathrm{R} \$ 10$ milhões. As novas regras aumentaram a segurança para o investidor, quando, por exemplo, o empreendedor passa a ser obrigado a fazer prestação de conta anual na plataforma da CVM e divulgar relatórios de resultados semestrais (Crowdinvest, [2017?]).

Entre 2016 e 2018, o número de plataformas aumentou de 4 para 14 . 0 total de investidores cresceu de 1.099 para 8.966. A captação total em 2018 foi no valor de R\$ 46 milhões, um crescimento de $451 \%$ em relação à 2016 (CVM, 2019). Ainda assim, a representatividade do ECF no mercado de investimentos é pequena, mesmo que promissora. Em 2017, os investidores-anjo aportaram R \$ 984 milhões em startups. Espera-se que até 2022 o ECF consiga arrecadar entre R\$ 150 e R $\$ 200$ milhões por ano (Crowdinvest, [2017?]).

Alguns dos motivos do crescimento do ECF são a dificuldade de empreendedores em obter capital em fontes tradicionais, como gestoras de Venture Capital, que preferem empresas maduras e com produtos testados pelo mercado (Berger \& Udell, 1998; Guenther et. al., 2018), a facilidade logística, possibilidade de usar sua própria base de clientes para se financiar e promoção através das plataformas (Estrin, 2018).

Os investidores de ECF são beneficiados pela chance de altos retornos sobre o valor investido e diversificação de portfólio (Estrin, 2018). No Brasil, é possível investir a partir de 500 reais. Essa modalidade de investimento é considerada arriscada, pois o investidor não tem garantias de que receberá seu dinheiro de volta, mas quando isso acontece os retornos são altos. Em 2019, a venda da startup Resale, que foi financiada através da plataforma Kria, para o banco BTG Pactual, gerou um retorno de até $128 \%$ em pouco menos de 3 anos (EXAME, 2019).

Como todas as interações entre investidores e empreendedores são online, governantes de diversos países consideram o ECF um valioso recurso para superar as limitações geográficas dos investimentos tradicionais (Guenther et. al., 2017). 


\subsection{Geografia do Crowdfunding}

Segundo Agrawal et al. (2011), uma das principais características do CF é a dispersão geográfica dos investidores. Em modelos de investimento tradicionais, investidores de empresas early stage tendem a ser locais porque é necessário levantar informações e monitorar o progresso do empreendimento e o custo dessas variáveis é sensível à distância (Agrawal et al., 2011; Agrawal et al. 2014). A distância média entre investidores de Venture Capital e as investidas é de aproximadamente $113 \mathrm{~km}$ (Agrawal et al., 2011 apud Sorenson \& Stuart, 2005). No Brasil, quanto mais longe uma empresa está das regiões que concentram Gestoras de Private Equity e Venture Capital, menor o número e o valor dos investimentos. Em seu estudo feito com dados secundários de 2010 da GVcepe, uma instituição de pesquisa brasileira focada em Private Equity e Venture Capital, Ventura (2015) encontrou que a distância média no país é de $274 \mathrm{~km}$.

A pesquisa de Guenther et al. (2017) sobre ECF na Austrália, utilizando uma base de dados de uma plataforma local com investidores domiciliados no país e fora dele, entre 2006 e 2012, encontrou evidências de que o investidor dessa modalidade tem comportamento semelhante ao de investidores tradicionais, ou seja, a distância impacta na decisão de investimento. Os principais motivos destacados foram que apesar da interação ser feita online ainda existem vantagens em investir em negócios próximos, por exemplo, a possibilidade de verificar a qualidade da empresa por meio de visitas e conversas com o empreendedor e funcionários.

No que diz respeito ao efeito da distância geográfica sobre o mercado brasileiro de CF, Mendesda-Silva, Conte, Gattaz, Chaves, \& Francisco (2015) analisaram a existência de associações entre a distância empreendimento-investidor e a disposição de investimentos nos empreendimentos de reward crowdfunding (CF de recompensas) de músicos, utilizando a base da plataforma Catarse em novembro de 2013. Os resultados fortalecem o pensamento acerca do valor de uma rede de contatos próxima sobre o financiamento, todavia, contrariam o argumento de que o CF pode suavizar o efeito inibidor da distância geográfica entre empreendimento-investidor.

Apesar do rápido crescimento e impacto, o ECF ainda é pouco estudado no Brasil. 0 presente estudo busca entender se a distância entre investidores e empresas impacta na decisão de investimento. A pergunta de pesquisa a ser respondida é: A distância é uma variável significativa na decisão e no valor do investimento em Equity Crowdfunding no Brasil?. As hipóteses testadas foram: $H_{0}$ : A distância entre Investidor e Empresa não impacta na decisão de investimento em ECF e $H_{1}$ : A distância entre Investidor e Empresa impacta na decisão de investimento em ECF.

A premissa de independência repousa no fato de que os aportes em empreendimentos de ECF têm valores reduzidos quando comparados com investimento em Venture Capital, conforme apontam Agrawal et al. (2011). Tendo em vista que os investidores não participam do dia a dia da empresa e toda a tramitação do investimento ocorre pela internet, parece não haver motivos para que pessoas que residam em áreas mais distantes não invistam nesse tipo de empreendimento (Guenther et al., 2017). Espera-se que haja uma maior concentração de investidores nas regiões Sul e Sudeste, porque é onde se concentram a maior parte da população e indústrias do Brasil, mas é esperado que também existam investidores de outras regiões.

\subsection{Regressões espaciais}

0 presente estudo busca entender o impacto da distância na decisão de investimento e no número de investidores em iniciativas que buscam financiamento através de ECF no Brasil. É necessário também considerar o espaço geográfico onde os agentes estão inseridos. A distância implica localizações com diferentes portes, número de pessoas, desenvolvimento econômico, tecnologia, entre outros fatores que impactam diretamente na decisão de investimento.

Uma das maneiras de incorporar o espaço geográfico nos modelos preditivos é incluir termos autorregressivos espaciais baseados em proximidade ou adjacência, por exemplo, por meio de Matrizes de Vizinhança, definidas por contiguidade ou distância. As variáveis de uma regressão são muitas vezes dependentes entre si espacialmente, isto é, o comportamento de uma variável é influenciado pelo comportamento dos seus vizinhos. Recomenda-se que seja feita uma análise da distribuição espacial das variáveis estudadas e uma formulação teórica prévia para ajudar a determinar o critério que será utilizado na construção da matriz (Francisco, 2010).

Uma das maneiras de estudar a dependência espacial da variável resposta é por meio do Modelo 
Espacial Autorregressivo (Spatial Auto-Regressive model - SAR). Nele, a matriz de vizinhança ( $W$ ) é incorporada como uma variável dependente espacialmente defasada $(W y)$ cuja influência é estimada pelo coeficiente espacial autorregressivo $(\rho)$. Nessa regressão, a hipótese nula é que não existe autocorrelação espacial (ou seja, $\rho=0$ ). A equação a seguir representa, na notação matricial, o modelo SAR:

\section{SAR: $y=\rho W y+X \beta+\varepsilon$}

Os modelos de regressão tradicionais, incluindo o SAR, são modelos globais, ou seja, buscam valores únicos, ou seja, "leis" advindas da similaridade no espaço. Existem também os modelos locais que consideram as diferenças entre as localizações estudadas, como por exemplo o Geographically Weighted Regression (GWR) (Francisco, 2010).

A técnica desenvolvida por Fotheringham, Charlton e Brunsdon (1997, 2002), por sua vez, consiste em uma série de regressões em que o parâmetro $(\beta)$ varia espacialmente. Para cada elemento espacial, configura-se uma regressão com uma amostra local e as variáveis independentes são ponderadas pela distância (ou outra medida de vizinhança). Sendo assim, o $\beta$ de cada variável explicativa varia conforme o ponto da regressão $g$ e sua amostra local.

$$
\text { GWR: } y(g)=\beta_{0}(g)+\beta_{1}(g) x_{1}+\beta_{2}(g) x_{2}+\beta_{3}(g) x_{3}+\cdots+\beta_{p}(g) x_{p}+\varepsilon
$$

\subsection{Teste de Heterocedasticidade}

De acordo com Wooldridge (2016), supõe-se que regressões lineares múltiplas são homocedásticas, isto é, a variância do erro não observável é constante. Sem a hipótese da homocedasticidade, os estimadores de variância são viesados, com isso os erros-padrão dos estimadores OLS (Ordinary LeastSquares), que dependem dessas variâncias, não são válidos para a construção de intervalos de confiança e estatística $t$ (que deixam de ter distribuições t, mesmo com o uso de grandes amostras).

A hipótese de homocedasticidade pode ser substituída pela hipótese mais fraca de que o erro ao quadrado não é correlacionado com todas as variáveis independentes. 0 teste de White (1980) testa formas de heterocedasticidades que invalidem os erros-padrão e as estatísticas de testes estimados pelo OLS nas regressões lineares múltiplas (Wooldridge, 2016).

Os testes de heterocedasticidade são baseados no teste de White. A hipótese nula é que dadas as variáveis independentes, o erro padrão possui variância constante. A hipótese alternativa é a presença de heterocedasticidade (Wooldridge, 2016).

\section{Metodologia}

\subsection{Base de dados}

Os dados utilizados nesse trabalho foram cedidos pela Broota (atualmente chamada de KRIA), a primeira plataforma de ECF do Brasil. A base foi extraída em 2016 e contém todos os projetos e investidores que utilizaram a plataforma entre 2015 e 2016. De acordo com a CVM (2016), 43 projetos foram financiados com ECF no Brasil em 2015, a base disponibilizada pela Broota continha 27 projetos, cerca de $63 \%$ do total.

\subsection{Funcionamento da Plataforma Broota}

A Broota ajuda empresas a levantarem capital e permite que elas fiquem expostas a mais de 2 mil investidores, que também servem como embaixadores do negócio dentro de suas próprias redes sociais (Broota, 2017). Qualquer empresa com CNPJ e faturamento inferior a $\mathrm{R} \$ 3,6$ milhões no ano anterior pode fazer uma Captação Pública através da Plataforma. Ao fazer o cadastro, o empreendedor cria o Perfil da Empresa, com informações sobre o negócio e preenche o documento "Termos da Rodada" com informações sobre quanto pretende captar, se o tipo de captação será por dívida ou participação acionária, avaliação da empresa (valuation) e a data de vencimento do Título no caso de dívidas (Broota, 2017).

A Broota faz uma avaliação preliminar dos dados fornecidos e caso a startup seja aprovada, serão exigidos documentos obrigatórios a serem submetidos à aprovação da CVM. Após a aprovação da Comissão, é possível iniciar a captação (Broota, 2017). A empresa tem, então, até 90 dias para captar 40\% da sua rodada online e até 180 dias para captar $90 \%$ do valor total. Caso não consiga arrecadar o valor até a data, a captação é encerrada e a empresa não recebe o dinheiro. Após captar R $\$ 150$ mil ou 90\% da rodada, é possível fazer a Chamada de Capital para assinar o contrato com os investidores e receber o 
dinheiro (Broota, 2017). Após o recebimento dos recursos, as startups são obrigadas a reportar seus resultados para os investidores quadrimestralmente por meio de Relatórios de Desempenho. A Figura 1 mostra uma empresa em fase de captação online:

Figura 1. Exemplo de empresa em fase de captação online na plataforma Broota.

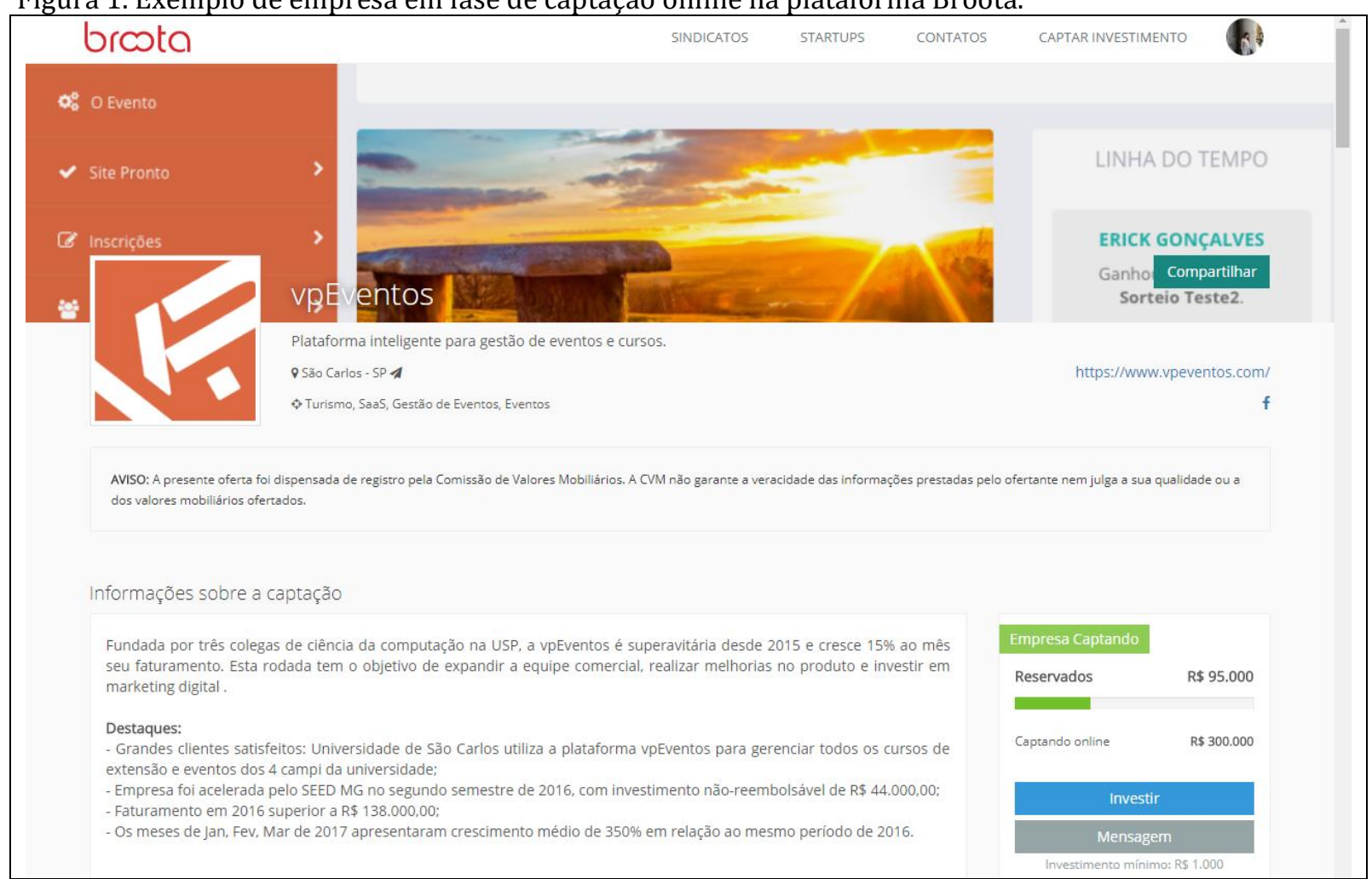

Fonte: Broota (2017).

O investidor precisa apenas ter CPF e concordar com os Termos de Uso da plataforma. É necessário fazer um cadastro com informações pessoais e pretensão de investimento. 0 investidor seleciona as empresas que considera interessantes e faz uma Análise das Ofertas, etapa na qual verifica as informações disponíveis, pede acesso a outros documentos que considera importantes e tira dúvidas com os empreendedores. Caso decida prosseguir, ele faz a Reserva de Investimento, na qual transfere o valor a ser investido para uma conta da Broota. Quando a empresa efetuar a Chamada de Capital, o investidor será convidado a assinar os contratos. Caso a startup não atinja o valor mínimo da rodada, o investidor é reembolsado (Broota, 2017).

O investimento mínimo por pessoa é de $\mathrm{R} \$ 1.000$ e ela paga uma taxa de $2 \%$ a $9 \%$ sobre o valor investido para a Plataforma. Esse custo é subtraído automaticamente do Título recebido. Os Títulos adquiridos não podem ser comercializados no Mercado Secundário, mas podem ser transferidos para outros investidores que estejam dentro das qualificações exigidas pela empresa.

\subsection{Perfil da base de dados}

A base utilizada no trabalho possui 1.152 observações referentes a 753 pessoas que fizeram Reserva de Capital nos 27 projetos disponíveis. A Tabela 2 resume as informações da base.

Tabela 2 - Informações presentes na base

\begin{tabular}{lll}
\hline Variável & № de Observações & Detalhamento \\
\hline Cidade da empresa & 1152 & 12 cidades em 07 estados \\
Cidade do investidor & 664 & 97 cidades em 23 estados \\
Estágio da empresa & 1152 & 04 em validação e 23 em expansão \\
Categoria da empresa & 1121 & 23 categorias \\
Investimento médio & 1152 & Média de R $\$ 7,9$ mil \\
\hline
\end{tabular}

Fonte: Elaborada pelos autores.

Durante a análise de dados foram excluídas observações com dados incompletos, devido a problemas no preenchimento do formulário no site da Broota. Excluímos 2 outliers, dois investimentos feitos 
pela mesma pessoa que tinham valor muito superior aos demais. Após o tratamento, restaram 631 observações referentes aos investimentos de 382 pessoas em 24 empresas diferentes. As 23 categorias de negócios foram agrupadas em 12 (Agricultura, Alimentação, Aplicativo, Beleza, Educação, Engenharia, Entregas, Gestão, Marketing, Marketplace, Pet e Saúde), conforme o segmento da empresa. Assumiu-se que o investimento de uma pessoa em uma empresa é igual ao seu respectivo investimento médio.

Os dados foram georreferenciados utilizando o serviço de busca por endereço automático batchgeo, disponível no site https://pt.batchgeo.com. A distância entre Empresas e Investidores foi calculada através do software ArcGIS Desktop Arcview 10.5 (ESRI, 2018). Foram acrescentadas informações geoeconômicas, PIB, PIB per capita, índice de Gini, tamanho e população do município das empresas e dos investidores, oriundas do IBGE (2010). 0 objetivo foi ponderar se os investimentos sofriam influência da riqueza das cidades das empresas ou dos investidores.

Após a análise preliminar da base de dados, foram feitas análises estatísticas descritivas e diversos testes de Regressões para determinar o melhor modelo.

$$
\mathrm{Y}=\beta o+\beta 1 \times 1+\beta 2 \times 2+\beta 3 \times 3+\cdots,+\beta n \times n+\varepsilon
$$

Tabela 3 - Variáveis independentes utilizadas nos modelos de regressão

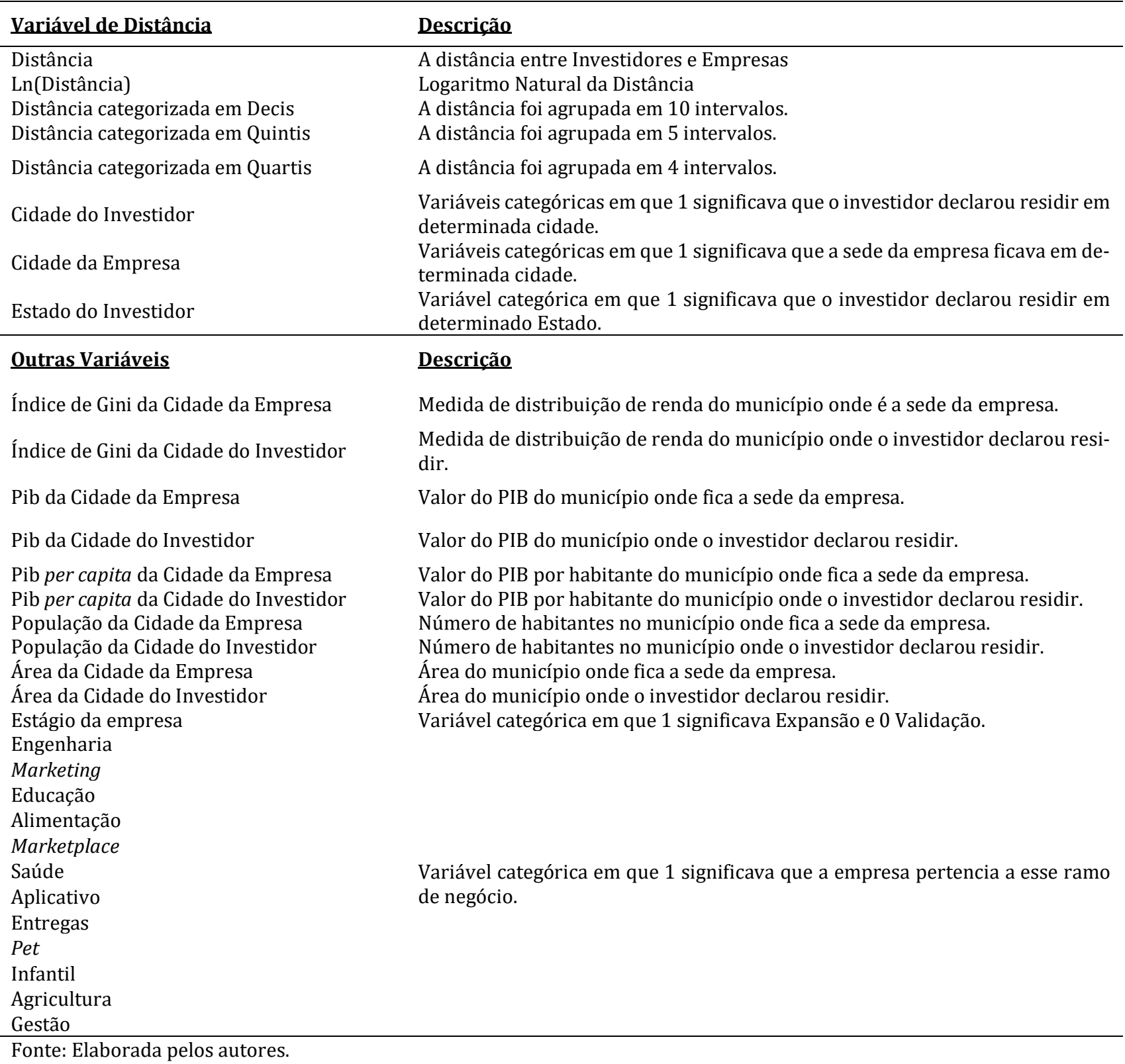

Para avaliar a hipótese de que a distância não impacta no valor investido, utilizamos uma variável 
dependente (y), o valor do Investimento Médio, testada em separado como o valor e o logaritmo neperiano (ln), ou natural, do Investimento Médio. 0 objetivo da transformação foi encontrar o melhor ajuste para a regressão e a melhor relação da variável dependente com suas regressoras. É usual utilizar o ln da variável original para diminuir sua variabilidade e mitigar aspectos de heterocedasticidade típicos de variáveis financeiras. As variáveis dependentes testadas estão descritas na Tabela 3.

As variáveis independentes foram testadas em diversas regressões lineares múltiplas, utilizando a ferramenta Minitab e foram desconsideras aquelas com valor-P maior que 5\%. Apenas a regressão com melhor ajuste foi promovida para o modelo Geoespacial utilizando o Geographically Weighted Regression (GWR). 0 objetivo foi manter as mesmas variáveis em todas as regressões e com isso tornar os resultados comparáveis. Tradicionalmente, a literatura de estatística espacial aplicada acaba promovendo os melhores modelos não espaciais multivariados para modelos espaciais para que se tenha a real observação do quanto a distribuição espacial melhora o poder de explicação.

\section{Resultados}

\subsection{Distância}

A distância entre Investidores e Empresas foi em média de $484 \mathrm{~km}$ com um desvio padrão de 555 $\mathrm{km}$. A Figura 2 mostra a localização das empresas e investidores sobrepostos e também ligados por uma linha que representa a menor distância entre investidor e a empresa em que ele investiu (configurando o chamado Spider Graph). A distribuição de Investidores por distância de Equity Crowdfunding é muito similar à distribuição de Private Equity e Venture Capital encontrada por Ventura (2015).

Figura 2. Localização das empresas e investidores

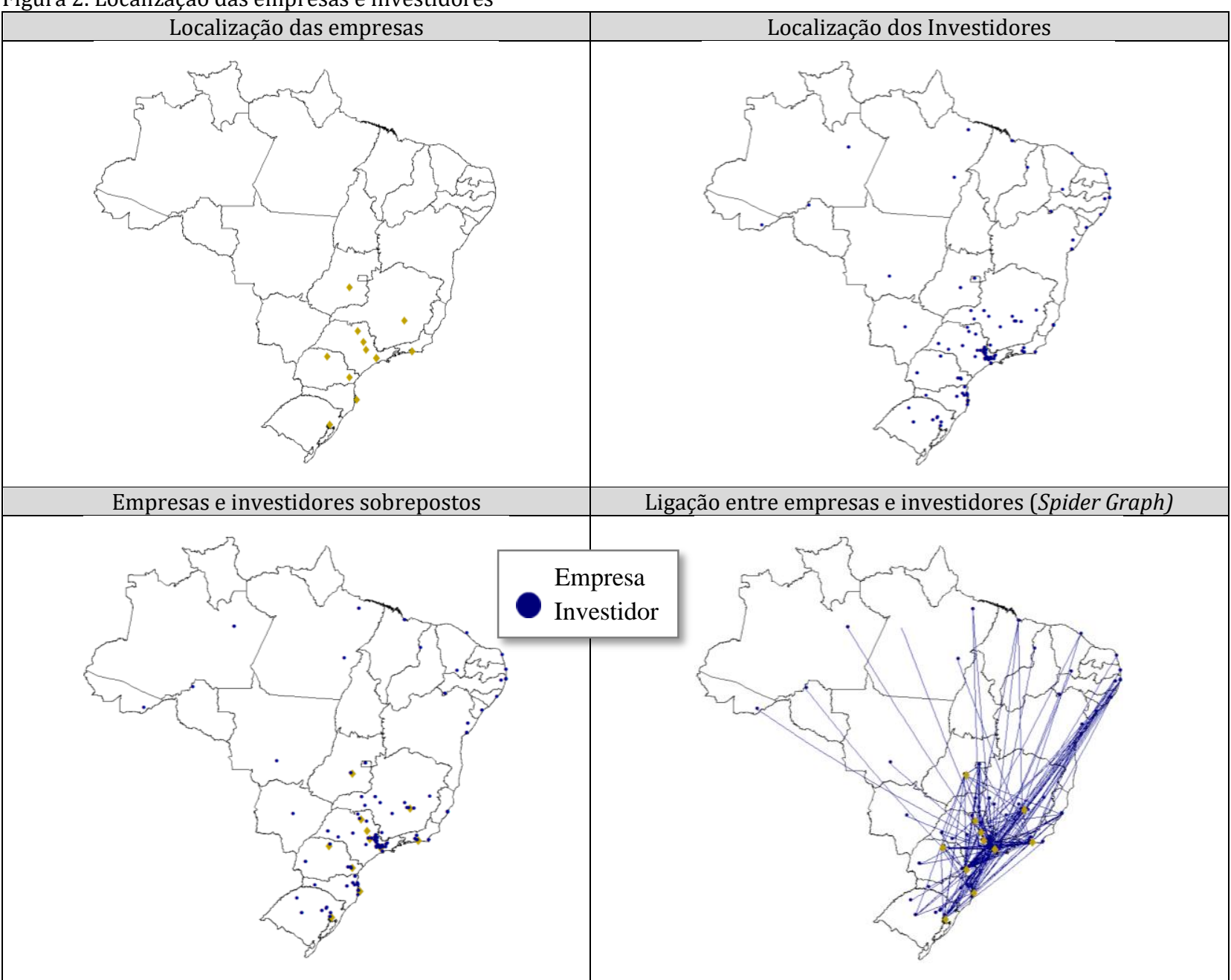

Fonte: Elaborada pelos autores utilizando o software Arcgis Desktop arcview 10.5 (ESRI, 2018).

A Tabela 4 apresenta dados estatísticos descritivos sobre a distância nas duas modalidades de 
investimento.

Tabela 4. - Informações sobre Distância (km) em ECF e PE/VC

\begin{tabular}{c|c|c|c|c|c|c}
\hline & $\begin{array}{c}\text { No de Observa- } \\
\text { ções }\end{array}$ & Média & Mediana & Min. & Máx. & Desv. Pad. \\
\hline ECF & 631 & 484 & 361 & 0 & 2.970 & 555 \\
\hline PE/VC & 551 & 429 & 347 & 0 & 2594 & 565 \\
\hline
\end{tabular}

Fonte: Elaborada pelos autores utilizando a ferramenta Minitab e adaptado de Ventura (2015).

A Figura 3 apresenta o número de investidores por categorias de distância em Equity Crowdfunding e Private Equity e Venture capital. Nela, é possível observar a semelhança no número de investidores por categoria de distância nas modalidades de investimento.

Figura 3. Histograma de distância entre investidores de ECF e empresas (esquerda) histograma de distância entre investidores de PV/ECF e empresas (direita).
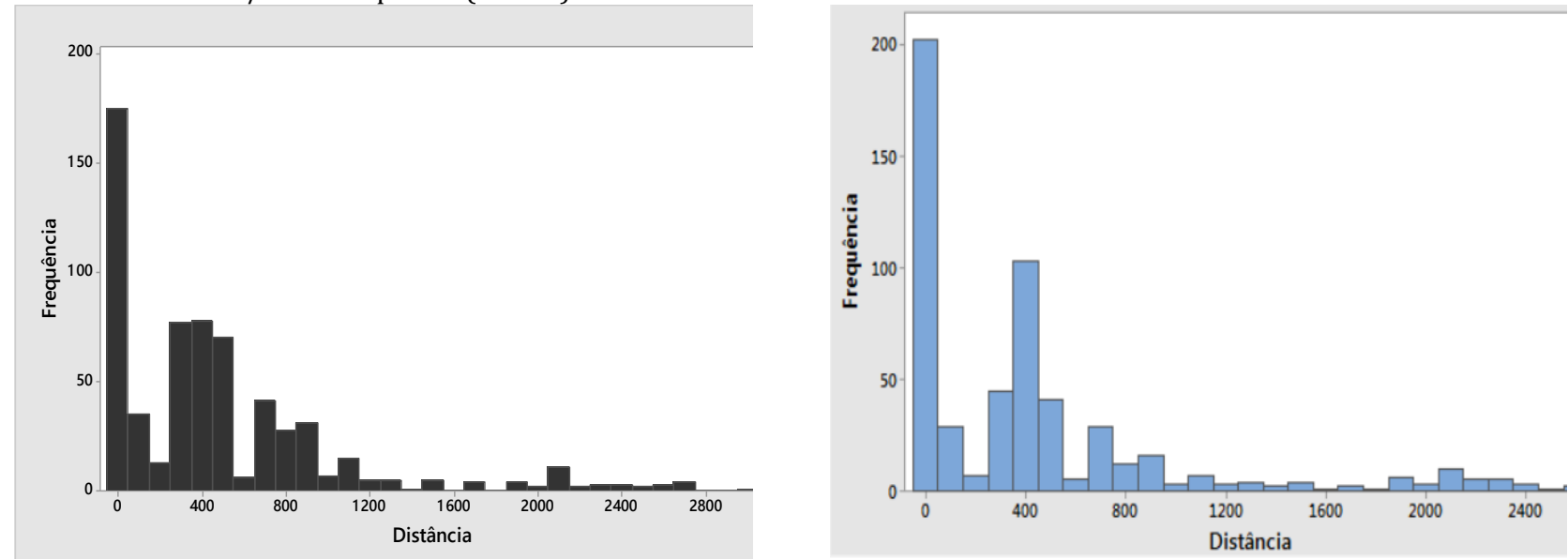

Fonte: Elaborada pelos autores utilizando a ferramenta Minitab e adaptada de Ventura (2015).

A Tabela 5 evidencia a comparação da porcentagem de investimentos por faixas de distância em ECF e PE/VC. Os dados estatísticos descritivos e a distribuição dos investidores por faixas de distância mostram que investidores de Equity Crowdfunding têm um comportamento semelhante ao de investidores de Private Equity e Venture Capital. 0 maior número de investimentos, em ambos estudos, se deu em um raio de até $50 \mathrm{~km}$ e conforme a distância aumenta, diminui-se o número de investimentos. Esses resultados vão contra a hipótese nula deste trabalho (a distância entre Investidor e Empresa não impacta na decisão de investimento em Equity Crowdfunding).

A porcentagem de empresas investidas foge do padrão de queda no número de investidores, conforme aumenta a distância nos intervalos de $250 \mathrm{~km}$ a $550 \mathrm{~km}$ e $650 \mathrm{~km}$ a $950 \mathrm{em}$ ambas as modalidades, conforme destacado em vermelho na Tabela 5.

Tabela 5 - Porcentagem de investimentos em ECF e PE/VC

\begin{tabular}{l|lll}
\hline Faixa & \% Investimentos ECF & \% Investimentos PE/VC & \multicolumn{1}{l}{$\begin{array}{l}\text { Variação } \\
\text { (ECF - PE/VC) }\end{array}$} \\
\hline $0-50 \mathrm{~km}$ & $27,7 \%$ & $36,7 \%$ & $-9,0 \%$ \\
$50-150 \mathrm{~km}$ & $5,5 \%$ & $5,3 \%$ & $0,2 \%$ \\
$150-250 \mathrm{~km}$ & $2,1 \%$ & $1,3 \%$ & $0,8 \%$ \\
\hline $250-350 \mathrm{~km}$ & $12,2 \%$ & $8,2 \%$ & $4,0 \%$ \\
$350-450 \mathrm{~km}$ & $12,4 \%$ & $18,7 \%$ & $-6,3 \%$ \\
$450-550 \mathrm{~km}$ & $11,1 \%$ & $7,4 \%$ & $3,7 \%$ \\
$550-650 \mathrm{~km}$ & $1,0 \%$ & $0,9 \%$ & $0,1 \%$ \\
$650-750 \mathrm{~km}$ & $6,5 \%$ & $5,3 \%$ & $1,2 \%$ \\
$750-850 \mathrm{~km}$ & $4,4 \%$ & $2,2 \%$ & $2,2 \%$ \\
$850-950 \mathrm{~km}$ & $4,9 \%$ & $2,9 \%$ & $2,0 \%$ \\
$950-1050 \mathrm{~km}$ & $1,1 \%$ & $0,5 \%$ & $0,6 \%$ \\
Mais de $1050 \mathrm{~km}$ & $11,1 \%$ & $10,7 \%$ & $0,4 \%$ \\
\hline
\end{tabular}

Fonte: Elaborada pelos autores utilizando a ferramenta Minitab e adaptada de Ventura (2015).

Ventura (2015) apontou que essas diferenças se dão porque na primeira faixa estavam concentradas startups que já estavam em expansão e, na segunda faixa, empresas totalmente consolidadas que 
já recebiam investimentos de Private Equity, portanto, em ambos os casos as empresas já estavam em estágios mais desenvolvidos e por isso apresentavam menor risco, o que explica o aporte de capital apesar da distância. No caso de Equity Crowdfunding, quase todos os investimentos (86,2\%) foram feitos em empresas que estavam em expansão, sendo assim, não é possível afirmar que o aumento de investimentos nessas faixas se deu porque há menor grau de risco. Supõe-se que dada a concentração de empresas (67\%) e investidores (49\%) na cidade de São Paulo, a faixa de $0 \mathrm{~km}$ a $50 \mathrm{~km}$ ficou com a maior parte dos investidores.

Entre $50 \mathrm{~km}$ e $250 \mathrm{~km}$, os investidores ainda estão dentro do Estado de São Paulo, mas poucas pessoas do interior fizeram aporte. Conforme apresentado na Figura 4, apenas entre $250 \mathrm{~km}$ e $550 \mathrm{~km}$ são abrangidas as capitais de Minas Gerais, Rio de Janeiro, Santa Catarina e Paraná. Entre 550 km e 650 km não há grandes cidades, por isso o número de investidores é reduzido neste intervalo. Entre $650 \mathrm{~km}$ e 950 km, o raio contempla Brasília e as capitais do Espírito Santo e do Rio Grande do Sul.

Vale ressaltar também que $72,6 \%$ dos investidores residiam na capital dos respectivos Estados. Sendo assim, há fortes indícios de que moradores de grandes regiões metropolitanas são mais propensos a investir em ECF.

Figura 4. Raios de distância a partir de São Paulo (esquerda) e número de investidores por Estado e porcentagens acumuladas selecionadas (direita)
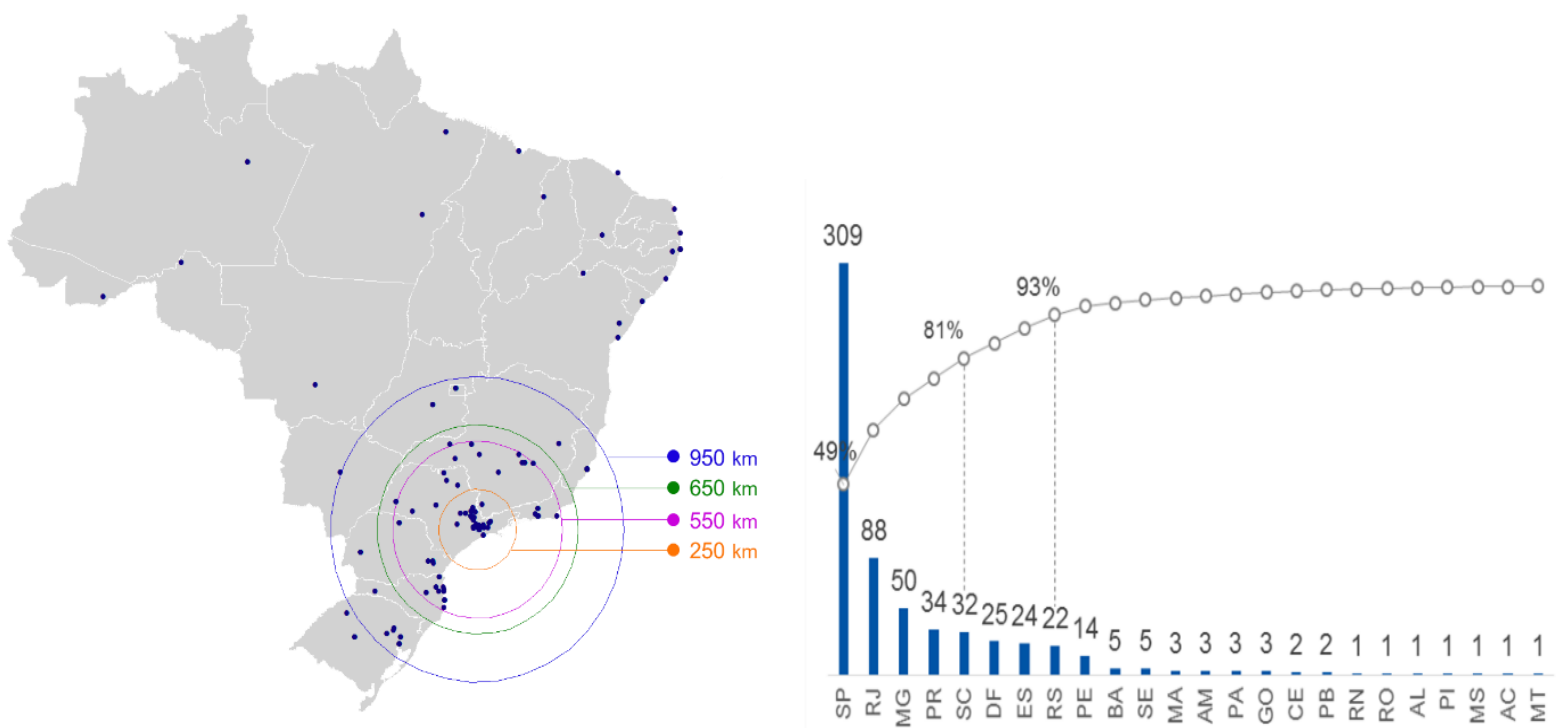

Fonte: Elaborada pelos autores utilizando a ferramenta ArcGIS Desktop ArcView 10.5 (ESRI, 2018).

\subsection{Valor Investido}

Os investimentos apresentaram desvio padrão elevado. A Tabela 6 resume as informações estatísticas descritivas encontradas:

Tabela 6 - Informações sobre Investimento em ECF

\begin{tabular}{l|l|l|l|l|l}
\hline Observações & Média & Mediana & Min. & Máx. & Desv. Pad. \\
\hline 631 & $\mathrm{R} \$ 7.344,00$ & $\mathrm{R} \$ 5.000,00$ & $\mathrm{R} \$ 1.000,00$ & $\mathrm{R} \$ 100.000,00$ & $\mathrm{R} \$ 9.958,00$ \\
\hline
\end{tabular}

Fonte: Elaborada pelos autores utilizando a ferramenta Minitab.

Conforme pode ser visto na Figura 5, a maioria dos investimentos teve valor inferior a $\mathrm{R} \$ 20.000$ e ficou concentrada em até $1.500 \mathrm{~km}$ da empresa investida. Os investimentos acima de $\mathrm{R} \$ 20.000$ ficaram concentrados em até $1.000 \mathrm{~km}$, uma distância que pode ser percorrida de avião em aproximadamente 1:40 horas, portanto perto o suficiente para grandes investidores (segundo Agrawal et al. (2011), $50 \%$ dos investidores anjo ficam localizados dentro de uma distância que pode ser percorrida em até meio dia de viagem). Um dos investidores destoou da relação de valor investido e distância; ele aportou em média R \$ 151.500,00 em empresas que estavam há mais de $2.000 \mathrm{~km}$, portanto foi considerado um outlier e excluído da base. 
Figura 5. Gráfico de Dispersão Investimento Médio em ECF Versus Distância

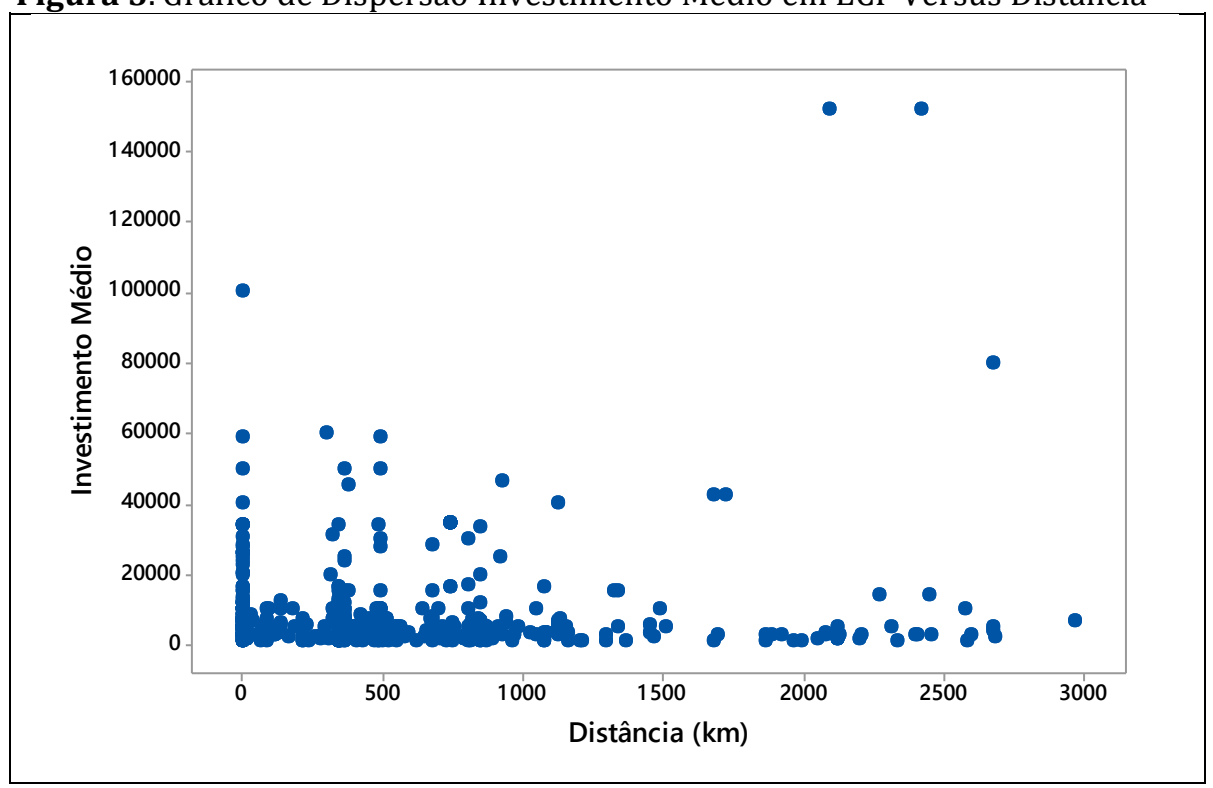

Fonte: Elaborado pelos autores utilizando a ferramenta Minitab.

São Paulo e Rio de Janeiro foram os Estados que aportaram mais capital (R\$2.464 mil e R \$ 621 mil respectivamente). 0 Amazonas foi o que investiu o maior valor por pessoa (R\$ 30 mil com 3 investidores), seguido por Sergipe (R\$ 18 mil com 5 investidores).

Figura 6. Investimento total por Estado (esquerda) e investimento médio por Estado (direita)

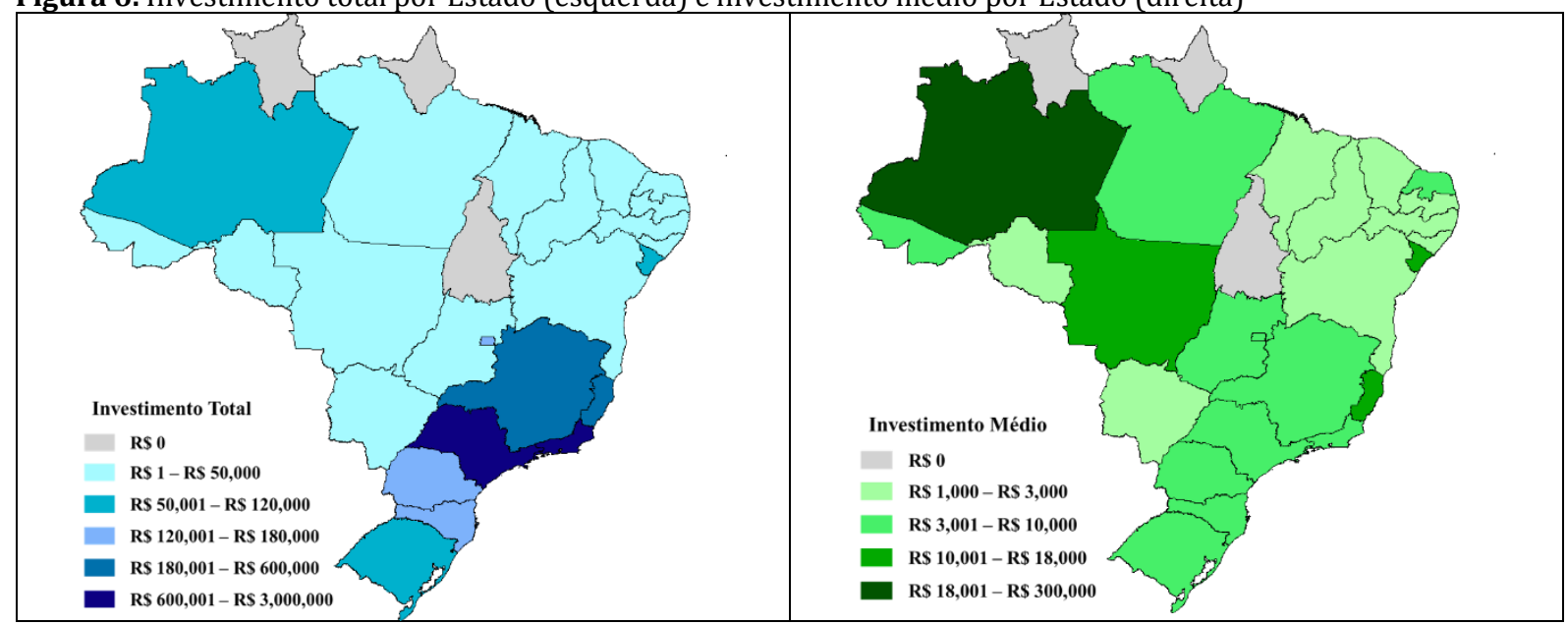

Fonte: Elaborada pelos autores utilizando software ArcView Gis 3.2.

Analisou-se de forma preliminar a influência do PIB per capita e a do Índice de Gini sobre o valor investido, mas não foi encontrada nenhuma relação evidente. Parece existir uma relação inversa positiva entre pior distribuição de renda e valor investido, ou seja, quanto pior a distribuição de renda da cidade maior o valor investido. Isso se deu em partes devido ao grande número de investimentos em São Paulo, que tem um Índice de Gini de 0,65 e 224 (35\% do total analisado), com investimentos variando entre R \$ 1.000 e R \$100.000. Se excluirmos os investimentos feitos em São Paulo, parece não haver uma relação clara entre a Distribuição de Renda e Valor Investido.

\subsection{Regressões lineares}

Foram feitas regressões lineares múltiplas, alternando o Valor do Investimento e o $\ln$ (Valor do Investimento) como variável dependente (Y) e a Distância, o $\ln$ (Distância) e a Distância agrupada em Decis, Quintis e Quartis, como variáveis independentes. 0 objetivo era testar qual modelo traria um melhor ajuste. As demais variáveis independentes foram mantidas em seu formato original. $\mathrm{O}$ valor-P de corte (alfa a priori) foi $5 \%$. 
0 maior $\mathrm{R}^{2}$ se deu com a Regressão do Investimento com a Cidade do Investidor $\left(\mathrm{R}^{2}=51,58 \%\right)$, mas dado o grande número de cidades e consequentemente de categorias (97), o ajuste provavelmente se deu para essa base específica e não seria aplicável para outras situações. Para contornar o problema, utilizamos os Estados dos Investidores ao invés das Cidades, mas tanto na regressão com Investimento como no modelo com In(Investimento) nenhum Estado obteve um valor-P inferior a 5\%. Refizemos a regressão incluindo a distância em Quartis (o segundo melhor resultado com $R^{2}=9,31 \%$ ), e mais uma vez nenhum Estado foi incluído entre as variáveis significativas. Os melhores ajustes se deram com o $\ln \left(\right.$ Investimento) como variável dependente. A Tabela 7 mostra o valor-P e $\mathrm{R}^{2}$ dessas regressões. 0 " $\mathrm{X}$ " representa o tipo de distância que foi usado em cada regressão, mas que não obteve valor-P menor que $5 \%$.

Tabela 7 - Valor - P e coeficiente das variáveis independentes e $\mathrm{R}^{2}$ das regressões com $\ln ($ Investimento) e Ditância

\begin{tabular}{|c|c|c|c|c|c|c|}
\hline & & Modelo I & Modelo II & Modelo III & Modelo IV & Modelo V \\
\hline Distância & & $\mathrm{X}$ & - & - & - & - \\
\hline Ln(Distância) & & - & $\mathrm{X}$ & - & - & - \\
\hline Distância categorizada em Decis & & - & - & $\mathrm{X}$ & - & - \\
\hline $\begin{array}{l}\text { Distância categorizada em } \\
\text { Quintis }\end{array}$ & & - & - & - & $\mathrm{X}$ & - \\
\hline \multirow[t]{2}{*}{$\begin{array}{l}\text { Distância categorizada em } \\
\text { Quartis }\end{array}$} & Valor-P & - & - & - & - & $\begin{array}{c}2^{\circ} \text { Quartil } \\
(9 \mathrm{~km}-360 \mathrm{~km}) \\
0,048\end{array}$ \\
\hline & Coeficiente & - & - & - & - & $-0,146$ \\
\hline \multirow{2}{*}{$\begin{array}{l}\text { População da Cidade do Investi- } \\
\text { dor }\end{array}$} & Valor-P & 0,000 & 0,000 & 0,000 & 0,000 & 0,000 \\
\hline & Coeficiente & 0,000 & 0,000 & 0,000 & 0,000 & 0,000 \\
\hline \multirow{2}{*}{ Engenharia } & Valor-P & 0,003 & 0,003 & 0,002 & 0,002 & 0,003 \\
\hline & Coeficiente & 0,402 & 0,402 & 0,412 & 0,412 & 0,392 \\
\hline \multirow{2}{*}{ Alimentação } & Valor-P & 0,000 & 0,000 & 0,000 & 0,000 & 0,000 \\
\hline & Coeficiente & 1,002 & 1,002 & 1,012 & 1,012 & 0,990 \\
\hline \multirow{2}{*}{ Pet } & Valor-P & 0,016 & 0,016 & 0,011 & 0,011 & 0,009 \\
\hline & Coeficiente & 0,474 & 0,474 & 0,488 & 0,488 & 0,502 \\
\hline \multirow{2}{*}{ Gestão } & Valor-P & 0,041 & 0,041 & 0,026 & 0,026 & 0,028 \\
\hline & Coeficiente & 0,276 & 0,276 & 0,292 & 0,292 & 0,287 \\
\hline Constante & Coeficiente & 8,193 & 8,193 & 8,164 & 8,164 & 8,212 \\
\hline $\mathrm{R}^{2}$ & & $7,64 \%$ & $7,64 \%$ & $8,74 \%$ & $8,74 \%$ & $9,31 \%$ \\
\hline
\end{tabular}

Fonte: Elaborada pelos autores utilizando o software Minitab.

Selecionamos as variáveis significantes da regressão com distância em Quartis (melhor ajuste) para evoluir para as Regressões Espaciais. Foram mantidos população do município do investidor, categoria Engenharia, categoria Alimentação, Pet, Gestão e o 2o Quartil de distância entre empresa e investidor (entre $9 \mathrm{~km}$ e $360 \mathrm{~km}$ ). As demais regressões foram feitas no R Studio (2019). A Tabela 8 apresenta o resultado da regressão linear múltipla. A variáveis com maior poder explicativo foram as categorias Alimentação e Pet.

Tabela 8 - Resultado da Regressão Linear Múltipla (RLM) de ln(Investimento) por Distância categorizada em Quartis e demais variáveis

\begin{tabular}{lll}
\hline Atributos & Coeficiente & Valor $-\mathbf{p}$ \\
\hline Alimentação & 0,990 & 0,000 \\
Pet & 0,502 & 0,009 \\
Engenharia & 0,392 & 0,003 \\
Gestão & 0,287 & 0,028 \\
$2^{\text {o Quartil }}$ & $-0,146$ & 0,048 \\
População da cidade do investidor & 0,000 & 0,000 \\
Constante & 8,212 & 0,000 \\
\hline AIC & 1605,521 & \\
Adj. R & $9,315 \%$ & \\
Valor-P & 0,00 &
\end{tabular}


Após a definição das variáveis, foi feito um teste de Heterocedasticidade, que busca a dependência entre os resíduos do modelo e as variáveis independentes, utilizando o software Oxmetrics (2013). Nesse teste, a hipótese nula é que o erro padrão possui variância constante, portanto pode ser usado para a construção de intervalos de confiança e estatística t. A hipótese alternativa é a presença de heterocedasticidade (Wooldridge, 2016). Os resultados do Hetero test e Hetro-X test foram 7,68\%, o que não rejeita a hipótese nula para $\alpha=10 \%$, permitindo concluir que os resíduos são homocedásticos, sendo, portanto, o modelo adequado. A Tabela 9 evidencia o resultado do teste.

Tabela 9 - Teste de Heterocedasticidade

\begin{tabular}{ll}
\hline Atributos & Coeficiente \\
\hline Alimentação & 0,990264 \\
Pet & 0,502048 \\
Engenharia & 0,391675 \\
Gestão & 0,287151 \\
$2^{\circ}$ Quartil & $-0,146251$ \\
Constante & 8,21238 \\
\hline Sigma & 0,857413 \\
Adj. $\mathrm{R}^{2}$ & $8,44 \%$ \\
Chi^2(2) & $44,743[0,0000]^{* *}$ \\
Hetero test & $\mathrm{F}(7.623)=1,8421[0,0768]$ \\
Hetero-X test: & $\mathrm{F}(7.623)=1,8421[0,0768]$ \\
RESET23 test: & $\mathrm{F}(2.622)=2,5776[0,0768]$ \\
\hline Fonte: Elaborada pelos autores utilizando 0 software 0ximetrics
\end{tabular}

\subsection{Estatística Espacial}

\subsubsection{Matriz de Vizinhança e Modelo Espacial Autorregressivo (SAR)}

As variáveis de uma regressão são muitas vezes dependentes espacialmente, isto é, o comportamento de uma variável é influenciado pelo comportamento dos seus vizinhos (Francisco, 2010). Por isso, incorporamos o espaço geográfico no modelo preditivo utilizando matrizes de vizinhança. Uma abordagem semelhante foi feita por Ventura (2015) para estudar o impacto da distância nos investimentos de Private Equity no Brasil. 0 critério utilizado foi número de vizinhos por observação. Para determinar quantos vizinhos cada investidor teria, fez-se uma simulação no software R Studio (2019) no qual matrizes de vizinhança eram criadas com o número de vizinhos variando entre 10 e 630 (a base contém 631 observações), essas matrizes eram então testadas no SAR. 0 critério utilizado para definir o número de vizinhos foi o modelo SAR com maior $\mathrm{R}^{2}$, o que se deu com 15 vizinhos. A Tabela 10 apresenta o resultado da regressão.

\begin{tabular}{lll} 
Tabela 10 - Regressão SAR & & \\
\hline $\begin{array}{l}\text { kGauss } \\
\text { (número de vizinhos) }\end{array}$ & 15 & \\
\hline Atributos & Coeficiente & Valor - p \\
\hline Alimentação & 0,984 & 0,000 \\
Pet & 0,514 & 0,007 \\
Engenharia & 0,239 & 0,094 \\
Gestão & 0,299 & 0,021 \\
2o-Quartil & $-0,132$ & 0,073 \\
PopMunInv & 0,000 & 0,000 \\
Constante & 8,161 & 0,000 \\
\hline AIC & 1600,6 & \\
Adj. R & $10,299 \%$ & \\
Valor-P & 0.009 & \\
\hline
\end{tabular}

Fonte: Elaborada pelos autores utilizando o software R Studio.

$$
\operatorname{Ln}(\text { Investimento })=8,16+(0,0 \times \text { PopMunInv })+(0,98 \text { x Alimentação })+(0,5 x \text { Pet })+(0,01 x \text { Wy })
$$

O impacto das variáveis independentes sobre o valor investido aumentou, o que prova que essas variáveis possuem dependência espacial, ou seja, o comportamento de um investidor é afetado pelo comportamento dos seus 15 vizinhos mais próximos. Como a matriz de vizinhança " $W y$ " apresentou um valor-P menor que 5\%, rejeitou-se a hipótese nula deste trabalho: $H_{0}$ : A distância entre Investidor e Empresa não impacta na decisão de investimento em ECF. 


\subsubsection{Regressão Ponderada Geograficamente (GWR)}

0 primeiro passo para aplicar o modelo GWR foi determinar a largura de banda dentro da qual as observações são consideradas vizinhas. 0 critério utilizado foi a largura de banda que minimizava o Akaike Information Criterion (AIC) da regressão estudada. Utilizou-se a função "gwr.sel" da extensão spgwr do software R Studio (2019) com a opção de kernel adaptativo, isto é, a largura de banda variava conforme a densidade de observações, ou seja, regiões com maior número de investidores possuíam larguras de banda menores do que lugares com baixa densidade. 0 melhor resultado se deu com uma largura de banda de $76,38 \%$, o que representa a porcentagem de observações mais próximas que são consideradas vizinhas.

A largura de banda encontrada foi utilizada nas regressões do modelo GWR. 0 resultado é apresentado na Tabela 11.

Tabela 11 - Regressão GWR

\begin{tabular}{|c|c|c|c|c|c|c|}
\hline Kernel adaptativo & 0,764 (aprc & adamente 48 & de 631 & & & \\
\hline Atributos & Min. & 19 Quartil & Média & 3 Quartil & Máx. & Global \\
\hline Alimentação & 0,710 & 0,710 & 0,823 & 0,901 & 1,054 & 0,990 \\
\hline Pet & 0,445 & 0,449 & 0,449 & 0,479 & 0,561 & 0,502 \\
\hline Engenharia & 0,359 & 0,364 & 0,364 & 0,379 & 0,414 & 0,392 \\
\hline Gestão & 0,250 & 0,250 & 0,267 & 0,281 & 0,319 & 0,287 \\
\hline $2^{\circ}$.Q.uartil & $-0,194$ & $-0,192$ & $-0,192$ & $-0,172$ & $-0,131$ & $-0,146$ \\
\hline Constante & 8,178 & 8,270 & 8,311 & 8,311 & 8,329 & 8,212 \\
\hline AIC & 1591.194 & & & & & \\
\hline Adj. $R^{2}$ & $10,42 \%$ & & & & & \\
\hline
\end{tabular}

Fonte: Elaborada pelos autores utilizando o software R Studio.

O GWR foi o que obteve o melhor ajuste em termos de $\mathrm{R}^{2}$ e AIC. Vale notar que impacto do $2^{\underline{o}}$ Quartil da distância no valor investido aumentou (em módulo) consideravelmente neste modelo (de 0,146 na RLM para -0,194 no GWR).

\subsection{Resumo dos modelos}

entre os modelos utilizados, o melhor ajuste se deu com o GWR que apresentou simultaneamente o maior $\mathrm{R}^{2}$ e o menor AIC. As variáveis estudadas têm, portanto, dependência espacial, isto é, o comportamento dos vizinhos de uma variável interfere no comportamento dela própria. Ainda assim, o incremento de explicação com uso de estatística espacial foi pequeno, o que leva a crer que o valor investido em ECF não depende fortemente da geografia. A Tabela 12 apresenta um resumo dos resultados:

Tabela 12 - Resumo dos resultados das regressões

\begin{tabular}{l|c|c|c}
\hline & RLM & SAR & GWR \\
\hline Adj. $\mathrm{R}^{2}$ & $9,31 \%$ & $10,30 \%$ & $10,42 \%$ \\
AIC & 1605,521 & 1600,6 & 1591,194 \\
\hline
\end{tabular}

Fonte: Elaborada pelos autores utilizando o software R Studio (2019).

\section{Considerações finais}

Os investidores de ECF, assim como o que foi encontrado por Agrawal et al. (2011) para Crowdfunding, apresentam uma dispersão geográfica maior do que a observada em Private Equity e Venture Capital. No estudo de Ventura (2015), as gestoras de fundos de Private Equity e Venture Capital concentravam-se em 6 Estados brasileiros, todos na região Sul-Sudeste, enquanto a base utilizada nesse trabalho indicava investidores em 24 Estados entre 2015 e 2016. Ainda assim, o número de investimentos por categorias de distância seguiu um comportamento similar ao encontrado por Ventura (2015) para Private Equity e Venture Capital e Felipe (2017), com a grande maioria dos investidores concentrados entre $0 \mathrm{~km}$ e $50 \mathrm{~km}$ das investidas e depois uma forte limitação no número de investimentos em função do aumento da distância geográfica. O número de investidores de ECF só tornou a aumentar quando as faixas de distância contemplavam as capitais dos estados, o que demonstra que essa modalidade de investimento é popular principalmente em regiões metropolitanas. 
Os resultados encontrados convergem com os encontrados por Guenther et. al. (2017). Apesar das informações serem disponibilizadas em plataformas online, o ECF não conseguiu contornar totalmente a sensibilidade do investidor à distância. Conforme aborda o autor, os investidores de ECF são suscetíveis home bias, tendência em investir em oportunidades locais.

As regressões apresentadas mostraram que a distância, desde que dentro de um intervalo de 9 $\mathrm{km}$ e $361 \mathrm{~km}$, impacta negativamente o valor investido em ECF, o que rejeita a hipótese nula de independência dos fatores proposta neste trabalho. A utilização de técnicas de estatística espacial levou a um melhor ajuste do modelo e maior capacidade de explicação da variável independente. 0 melhor resultado se deu com a aplicação do modelo GWR, que apresentou um $\mathrm{R}^{2}$ de $10,42 \%$, cerca de $0,12 \%$ maior que o resultado do SAR e 1,11\% maior que o OLS. 0 AIC também diminuiu com a utilização da geografia - mesmo com o acréscimo da variável Wy ao modelo, tornando-o menos parcimonioso. Percebe-se, portanto, que as variáveis têm dependência espacial significante; logo, a influência da variável dependente das features vizinhas mostrou contribuição ao modelo explicativo. Ainda assim, o benefício do incremento é considerado importante, o que leva a crer que a geografia é significante para explicar o valor investido em ECF, mas não tem um impacto elevado.

Não obstante, os modelos SAR e GWR mostraram-se equivalentes quanto ao efeito das variáveis espaciais. 0 modelo SAR permitiu realizar o teste sobre a hipótese da influência da distância entre Investidor e Empresa e mostrar a significância e a influência da variável distância e do termo espacial autorregressivo (Wy, Investimento nas observações vizinhas). Outrossim, o modelo GWR mostrou-se bem similar, na comparação através dos indicadores $\mathrm{R}^{2} \mathrm{e}$ AIC. Ambos os modelos, que apresentam motivações metodológicas diferentes na incorporação da influência espacial, mostraram-se satisfatórios.

Os resultados apresentados pelo trabalho são relevantes para os empreendedores, que passam a ter mais informações sobre variáveis que impactam no aporte de capital. Investidores podem usar os achados aqui evidenciados como um dos insumos para avaliar se uma startup terá sucesso, uma vez que fatores como categoria da empresa e localização são importantes para garantir a disponibilidade de capital, conforme sugere Mollick (2014) e Lehner e Harrer (2019). Agentes públicos que trabalham com desenvolvimento regional podem utilizar as conclusões para ajudar a definir quais empresas (afastadas de regiões metropolitanas) precisam de maior disponibilidade de crédito.

Recomenda-se que os próximos estudos investiguem o impacto dos investidores do círculo social do empreendedor sobre o número de investimentos e no valor investido em ECF no Brasil. É importante entender a participação desse tipo de investidor no número de aportes e as fases do ciclo de financiamento em que eles investem. Essa visão pode ser essencial para distinguir o quanto a necessidade de proximidade física encontrada neste estudo é derivada de investidores que têm relações pessoais e, portanto, outros motivos para aportar capital em um negócio, além do risco e possibilidade de retorno percebido. Outrossim, os achados provenientes de tal investigação poderiam ajudar a entender as motivações dos investidores em cada etapa do financiamento (Signori \& Vismara, 2018) e com isso o empreendedor teria mais subsídios para tornar a sua campanha de financiamento via ECF bem-sucedida (Cumming, Vanacker \& Zahra, 2019).

\section{Referências}

Agrawal, A. K., Catalini, C., \& Goldfarb, A. (2011). The geography of crowdfunding. Nber working paper series, Cambridge, n. 16820.

Agrawal, A., Catalini, C., \& Goldfarb, A. (2014) Some simple economics of crowdfunding. Innovation Policy and the Economy, v. 14, n. 1, p. 63-97.

Anbil, S. (2018). Managing stigma during a financial crisis. Journal of Financial Economics, 130(1), 166181.

Anglin, A. H., Short, J. C., Ketchen Jr, D. J., Allison, T. H., \& McKenny, A. F. (2019). Third-Party Signals in Crowdfunded Microfinance: The Role of Microfinance Institutions. Entrepreneurship Theory and Practice, 1042258719839709.

Batchgeo. Criar um mapa. Recuperado em 5 março, 2017 de https://pt.batchgeo.com.

Berger, A. N., Espinosa-Vega, P. I., Frame, W. S., \& Miller, N. H. (2011). Why do borrowers pledge collateral? New empirical evidence on the role of asymmetric information. Journal of Financial Intermediation, 20(1), 55-70.

Berger, A., \& Udell, G. (1998). The economics of small business finance: the roles of private equity and 
debt markets in the financial growth cycle. Journal of banking \& finance, [S.I], v. 22, n. 6, p. 613-673.

Broota. Como funciona. Recuperado em 22 maio, 2017, de https://www.broota.com.br/como-funciona

Brown, R., Mawson, S., Rowe, A., \& Mason, C. (2018). Working the crowd: Improvisational entrepreneurship and equity crowdfunding in nascent entrepreneurial ventures. International Small Business Journal, 36(2), 169-193.

Comissão de Valores Mobiliários. (2016). Edital de audiência pública noํ6/2016, de 6 de novembro de 2016. Investment-based crowdfunding, Rio de Janeiro.

Comissão de Valores Mobiliários. (2019). Número de investidores em crowdfunding cresce após regulamentação. Recuperado em 21 janeiro, 2019, de http://www.cvm.gov.br/noticias/arquivos/2019/20190429-1.html

Comissão de Valores Mobiliários. (2017). CVM regulamenta Crowdfunding de Investimento. Recuperado em 13 julho, 2017, de http://www.cvm.gov.br/noticias/arquivos/2017/20170713-2.html

Crowdinvest.[2017]. Equity Crowdfunding. Recuperado em 21 janeiro, 2020 de http://equity.org.br/equity-crowdfunding/

Crowdsourcing Week.(2017). Equity crowdfunding vs venture capital. Recuperado em 06 junho, 2017 de http://crowdsourcingweek.com/blog/equity-crowdfunding-vs-venture-capital

Cumming, D. J., Vanacker, T., \& Zahra, S. A. (2019). Equity crowdfunding and governance: Toward an integrative model and research agenda. Academy of Management Perspectives.

ESRI. (2018). Arcgis Desktop arcview: Release 10.2.1. Redlands, CA: Environmental Systems Research Institute.

Estrin, S., Gozman, D., \& Khavul, S. (2018). The evolution and adoption of equity crowdfunding: entrepreneur and investor entry into a new market. Small Business Economics, v. 51, n. 2, p. 425-439.

Exame. (2019). Equity crowdfunding conclui 1ํㅡ negócio e investidores lucram até $128 \%$. Recuperado em 16 novembro, 2019 de https://exame.abril.com.br/seu-dinheiro/equity-crowdfunding-conclui10-negocio-e-investidores-lucram-ate-128/

Exame. (2017). 3 sites de crowdfunding para sua ideia conquistar investidores. Recuperado em 21 janeiro, 2020 de https://exame.abril.com.br/pme/3-sites-de-crowdfunding-para-sua-ideia-conquistarinvestidores/

Felipe, I. (2017). Determinantes do sucesso de campanhas de equity e de reward crowdfunding. Dissertação de Doutorado, Universidade Federal de Ouro Preto, Ouro Preto, MG, Brasil

Felipe, Israel José dos Santos. (2015). Shared value creation and crowdfunding in Brazil. Journal of Financial Innovation, 1(3), 213-230. doi:10.15194/jofi_2015.v1.i3.39.

Felipe, I. J. Dos S.; Mendes-Da-Silva, W.; Gattaz, C. C. (2019). Crowdfunding research agenda: Semantic analysis of the media and geography of investments. Encyclopedia with Semantic Computing and Robotic Intelligence, 2(2), 1930001-119300010. Https://doi.org/10.1142/S2529737619300018.

Festel, G., Wuermseherb, M., \& Cattaneoc, G. (2013). Valuation of early stage high-tech start-up companies. International journal of business, [S.L.], v. 18, n. 3, p. 217-231.

Francisco, E. R. (2010). Indicadores de renda baseados em consumo de energia elétrica: abordagens domiciliar e regional na perspectiva da estatística espacial. 381 ps.

Guenther, C., Johan, S., \& Schweizer, Denis. (2017). Is the crowd sensitive to distance?-How investment decisions differ by investor type. Small Business Economics, v. 50, n. 2, p. 289-305.

Hildebrand, T., Puri, M., \& Rocholl, J. (2016). Adverse incentives in crowdfunding. Management Science. Hornuf, Lars; Schwienbacher, Armin. Market mechanisms and funding dynamics in equity crowdfunding. Journal of Corporate Finance, v. 50, p. 556-574, 2018.

Forbes. (2012). Inside the jobs act. Forbes. Recuperado em 6 junho, 2016 de https://www.forbes.com/sites/tanyaprive/2012/11/06/inside-the-jobs-act-equity-crowdfunding-2/\#5d142f584b2e

IBGE - Instituto Brasileiro de Geografia e Estatística. (2010). Censo 2010. Rio de Janeiro. Recuperado em 6 junho, 2017 de http://www.censo2010.ibge.gov.br/

Kabylka, Alena. (2016) Crowdfunding for non-commercial initiatives. Dissertação de Mestrado, Instituto Politécnico de Bragança da Associação de Politécnicos do Norte, Bragança, Brasil.

Lehner, O. M., \& Harrer, T. (2019). Crowdfunding revisited: a neo-institutional field-perspective. Venture Capital, 21(1), 75-96.

Marom, D., Robb, A., \& Sade, O. (2014). Gender Dynamics in Crowdfunding (Kickstarter): Evidence on Entrepreneurs, Investors, Deals, and Taste-Based Discrimination. SSRN Working Paper № 2442954, (430), 
$1-75$.

Mendes-da-Silva, W., Conte, L., Gattaz, B. S., Chaves, C., \& Francisco, E. R. (2015). The impacts of fundraising periods and geographic distance on financing music production via crowdfunding in Brazil. Journal of Cultural Economics, v. 40, n. 1, p. 75-99.

Mollick, E. (2014). The dynamics of crowdfunding: An exploratory study. Journal of business venturing, v. 29, n. 1, p. 1-16.

Mollick, E., \& Robb, A. (2016). Democratizing Innovation and Capital Access. California Management Review, 58(2), 72-87.

Oxmetrics 7. (2013). Integrated econometric and statistical software. Richmond: oxmetrics Technologies.

R Studio. (2019). Desktop Statistic Software. Version 1.2. Boston: FOAS; R CONSORTIUM.

Riffel, Melanie Giacobbo. (2016) Crowdfunding: de modismo a novo instrumento financeiro. Dissertação de Mestrado, Escola Brasileira de Administração Pública e de Empresas da Fundação Getulio Vargas, Rio de Janeiro, Brasil.

Ryan, R. M., O’Toole, C.M., \& McCann, F. (2014). Does bank market power affect SME financing constraints? Journal of Banking \& Finance, 49, 495-505.

Schwienbacher, A. (2019). Equity crowdfunding: anything to celebrate?. Venture Capital, v. 21, n. 1, p. 65-74.

Short, J. C., Ketchen Jr, D. J., McKenny, A. F., Allison, T. H., \& Ireland, R. D. (2017). Research on crowdfunding: Reviewing the (very recent) past and celebrating the present. Entrepreneurship Theory and Practice, 41(2), 149-160.

Agência SEBRAE de Notícias. (2019). Pequenos negócios foram responsáveis pela geração de mais de 580 mil vagas em 2018. Recuperado em 12 maio, 2019 de http://www.agenciasebrae.com.br/sites/asn/uf/NA/pequenos-negocios-foram-responsaveis-pela-geracao-de-mais-de-580-mil-vagasem-2018,bab731912eb78610vgnvcm1000004c00210arcrd/

Seed Invest. (2016). Risk of investing in startups. Recuperado em 6 junho, 2016 de https://www.seedinvest.com/academy/risks-of-investing-in-startups

Signori, A., \& Vismara, S. (2018). Does success bring success? The post-offering lives of equity-crowdfunded firms. Journal of Corporate Finance, 50, 575-591.

Ventura, Rodrigo. (2015) Organizações Gestoras e Clusters de Inovação: empreendedorismo, Venture Capital e Private Equity no Brasil. 2015. 51 f. Projeto de Pesquisa (Programa Institucional de Bolsas de Iniciação Científica - PIBIC) - Escola de Administração de Empresas de São Paulo, Fundação Getulio Vargas, São Paulo, SP, Brasil.

Vulkan, N., Åstebro, T., \& Sierra, M. F. (2016). Equity crowdfunding: A new phenomena. Journal of Business Venturing Insights, v. 5, p. 37-49.

Wang W., Mahmood, A., Sismeiro, C., \& Vulkan, N. (2019). The evolution of equity crowdfunding: Insights from co-investments of angels and the crowd. Research Policy.

Wooldridge, M. J. (2016). Introdução à Econometria uma abordagem moderna. São Paulo: Cenagage, 2016. $701 \mathrm{p}$.

Zhang, D., Juan, W., Dan, L., \& Yaokuang, L. (2018). Online or Not? What Factors Affect Equity Crowdfunding Platforms to Launch Projects Online in the Pre-Investment Stage?. Entrepreneurship Research Journal, v.9, n. 2. 